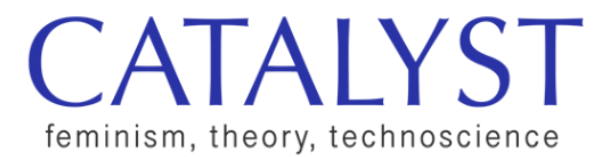

\title{
The Cyclic Self: Menstrual Cycle Tracking as Body Politics
}

\author{
Laetitia Della Bianca \\ University of Lausanne \\ laetitia.dellabianca@unil.ch
}

\begin{abstract}
This article explores to what extent, and under what conditions, practices of fertility self-tracking shape and are shaped by particular power relations. Drawing on twenty-six interviews with users of a specific fertility tracker, I argue that through these self-tracking practices, users shape a relationship with their body that I call "cyclic self-fashioning"-a process through which the datafied body becomes a catalyst for understanding and intervening on the self. The article analyzes the ways these technologies contribute to users' relationships with what emerges as the "fertile female body" and what comes to count as axiomatic about it. While at first glance the process of cyclic self-fashioning can be perceived as a reinforcement of biologism, it nonetheless challenges the appropriation by users of their biosociodigital body in everyday life. By focusing on practices that have received little attention so far in the self-tracking literature, the article shows how normative expectations in/of/from Western biomedicine about the fertile female body are used, challenged, or resisted by users in the pursuit of various purposes that extend beyond the optimization of an idealized reproductive body.
\end{abstract}

Della Bianca, Laetitia. 2021. "The Cyclic Self: Menstrual Cycle Tracking as Body Politics." Catalyst: Feminism, Theory, Technoscience 7 (1): 1-21. 
Technology is never simply just technology. It can be a tool or machine or the exchange of digital information, but it is also an idea, it has its historical moment and it is the site for the exercise of politics. -Mark Davis, "After the Clinic?"

Data itself neither reveals nor engenders possibilities for materialities with which we can live. That requires queer feminist imaginations and the critical work of making intelligible.

-Angela Willey, Undoing Monogamy

\section{Introduction}

Hundreds of mobile applications (apps) are available today to monitor the menstrual cycle. The most popular are downloaded by millions of people around the world. These technologies are marketed as tools to assist users in becoming pregnant, avoiding becoming pregnant, or, more generally, knowing their bodies. Developers' claims promise women empowerment through these technologies, yet criticisms abound about the entrepreneurial, self-optimizing female subject they promote. Both perspectives tend toward a narrow view of the subject, simply as prey to the techno-determining power of a singular technology. This article explores the extent to which, and under what conditions, technologically enhanced practices of menstrual cycle self-tracking shape and are shaped by power relations. It shows how users in pursuit of various purposes that extend beyond body optimization actively challenge normative expectations in/of/from Western biomedicine about the "fertile female body".

Drawing on twenty-six interviews with users of a fertility tracker, I argue that users create a relationship with their body via self-tracking practices that I call "cyclic self-fashioning"-a process through which the datafied body becomes a catalyst for understanding and intervening on the self. Building upon Joseph Dumit's (1998) concept of "objective self-fashioning," the "cyclic self" provides a heuristic to investigate the normative biosociotemporality of self-tracking practices that is particularly useful for analyzing the (mis)fits, (non-)alignments, and discrepancies that emerge between normative expectations and the lived realities of menstruating bodies.

This research contributes to feminist technoscience debates pertaining to the role of sciences and technologies in shaping human bodies. Following the call by Deboleena Roy and Banu Subramaniam (2016) to "do" biology differently, I undertake an analysis of the ways fertility-tracking technologies contribute to the 
user's relationship with the fertile female body and what becomes axiomatic about this body. At first glance, cyclic self-fashioning may be perceived as a reinforcement of biologism; however, I use this concept to explore how selftrackers bring particular "biopossibilities" into being (Willey 2016). My approach is situated in self-tracking scholarship that theorizes the body as a site for interpretation and challenges the singular conception of the neoliberal selftracking subject (Danesi et al. 2020; Henwood and Marent 2019; Sharon 2015, 2016; Weiner et al. 2020). Consistent with a socio-material practice-based approach that emphasizes the ambivalence and fluidity of users' engagements with technologies, I take investigation of the role of biotemporal mediated entities in everyday life a step further, by focusing on practices that have received little attention in the literature so far.

The analysis presented here is part of a larger ethnography on fertility tracking that investigates how knowledge about the potentially ovulating self is configured and enacted in practice. Between 2017 and 2020, I followed multiple contexts of "enactment" of a specific digital fertility tracker (Mol 2002). My fieldwork led me to designers' offices, manufacturing labs, customer service departments, international gynecological conferences, menstrual activists and natural family planning meetings, consumer expos, online discussion forums, and users' homes. The analyses reported here are drawn from online interviews with twenty-six users of the digital fertility tracker.

The twenty-six users I interviewed for this phase of my research participated in a customer satisfaction survey launched by the fertility tracker's company in February 2018. A few months prior, during my ethnographic observations at the company, my lead informant, a biologist aware of my interest in user experiences, suggested that the company add a question to the survey asking users if they would be willing to be contacted for an interview. After receiving affirmative responses and associated email addresses, I contacted potential interviewees with more information and offered to meet them in person or online for an interview depending on their location and preference. Except for two-in Switzerland and Denmark-all interviews were conducted online.

The aim of this phase of the study was to further develop an emerging theory of cyclic self-fashioning grounded in ethnographic research. For these purposes, I chose to analyze a small, random sample of 1,193 active users of the technology of interest without limiting eligibility to a particular nationality or age group. The sample varied demographically. Participants were between twenty-one and forty- 
two years old, mostly white, middle-class, and highly educated cisgender women. They were married, single, or in monogamous or polyamorous relationships. Some had children, and some didn't. Some were religious (Christian, Jewish), and others were not. All interviews were conducted in English, except for one in French. The interviews spread across different national contexts. Countries of residence included: Switzerland (3), Germany (1), Ireland (1), Denmark (2), Finland (1), the Cayman Islands (1), Italy (1), the United Kingdom (2), the United Arab Emirates (1), and the United States (13). Nine participants were no longer using the tracker at the time of the interview for reasons that will be revealed later.

All interviews were recorded, transcribed, and analyzed abductively to foster theory construction. Stefan Timmermans and Iddo Tavory (2012) argue that abductive analysis "rests on the cultivation of anomalous and surprising empirical findings against a background of multiple existing sociological theories and through systematic methodological analysis" (2012, 169). Thus, building upon my emerging theory of cyclic self-fashioning as a process of challenging normative expectations of the fertile female body, the analysis explores three research questions: (1) What does the digital fertility tracker promise its users, and what drives some people to use it? (2) What does it take for a person and their body to become a subject for whom this technology works? (3) What are the effects and affects produced in a model where anticipated cyclicity is the norm?

Findings show that the fertility tracker does more than measure fertility status at a point in time; it mediates the user's relationship with their body and others, and co-shapes their inscription in the world in ways intertwined with normative values. Consequently, it frames the fertile female body as a relational effect rather than a given entity ( $M^{\prime}$ charek 2010). The tracker rarely acquires a singular authoritative position. It is mobilized alongside other elements (books, online forums, partners, doctors, healers, medicinal foods, friends and families, ovulation kits, and others). The datafied menstrual cycle- a "datafied body double" (Horrocks 2019), operates as an active mediator between the embodied self and their body, based on a desired cyclical nature. The datafied cycle measures not only potential fertility status but also the value of social, environmental, and political relations. Its materialization mediates the affects of humor, hope, fear, joy, failure, and peace of mind. Yet cyclic self-fashioning through fertility tracking can also be seen as a form of "self-determined care" (Brown 2012). 


\section{Situating the Technology and Its Users}

"As easy as 1, 2, 3...Only about 60 seconds per day!" In 2014 Valley Electronics, a Germany-based company, launched a new fertility tracker called Daysy. The tracker was promoted as a stand-alone, computer-based thermometer that measures, records, analyzes, and displays a woman's ${ }^{1}$ estimated fertility status based on basal body temperature. Every morning, before getting out of bed, the user takes her temperature. Once measured, a color-coded light on the device reports her fertility status: green indicates that the user is not fertile; red signals that she is; and yellow means that the tracker doesn't know. Additionally, she can connect the tracker to a smartphone app to visualize her data, which appear either as colored days on a calendar or temperature values on a chart. The user is then expected to take appropriate and responsible contraceptive measures based on these colors.

Despite its apparent simplicity, the tracker is configured for a specific set of users who embody biological, social, and political adequacy. That is, they should have a nineteen- to forty-day menstrual cycle, educational and socioeconomic resources, and the power to choose when, and if, to have sexual intercourse that might result in pregnancy. This idealized user is most likely to be found in upper socioeconomic classes and Western industrialized countries, a hypothesis confirmed by the sociodemographics of the randomly selected users who agreed to participate in the interviews on which this analysis is based.

The device's categorization of the user's body into a colored fertility status results from a series of translations. Temperature is a proxy for hormonal change, which, in turn, is a proxy for ovulation, which is equated with fertility and conflated with fecundity. This equivalence chain is not new. It was developed during the twentieth century by Catholics and scientists who aligned their interests to construct a "vulnerable interlude of fertility" (Clarke 2000, 44), later referred to as "the fertile window." This time interval indicates the numbers of days in each cycle when an egg can be fertilized. The detection and algorithmic prediction of this temporary physiological state was embedded into various trackers by Valley Electronics since the 1980s. The tracker at the center of this analysis is the first developed by the company to omit numerical inscriptions completely, offering only a colored light to signify fertility status.

In shifting away from the numerical fertile window, the tracker turns the problem of contraception into one of fertilization avoidance (Mol 2015), similar to the pill and condoms or diaphragms. However, it differs from the pill in that the tracker 
establishes the vagina rather than the hormonal system as the "contraceptive frontier" (Clarke 2000, 61). It also differs from condoms or diaphragms by locating the contraceptive frontier in information rather than latex or silicone.

Situated within a tradition of revealing technologies for an informational body (Viseu and Suchman 2010), the fertility tracker promises to bring users closer to their bodies by making perceptible what would otherwise be unknown. Yet, the tracker promotes a specific form of body politics (Shaw 2008). First, through alignment with the slogan "knowledge is power," it capitalizes on 1970 feminist activism while redefining political struggle in terms of a consumer good. Second, empowerment is mediated through built-in constraints designed to alleviate potential errors. For example, users can neither measure their temperature twice in a certain time frame, nor edit it. Ultimately, the measurement, charting, and interpretational processes granted to users by design offer limited agency to users. A "technosexual script" (Waidzunas and Epstein 2015) spares users the burden of "superfluous" cognitive and contraceptive work. Users can rely on the "intelligent thermometer" to know when to use contraception instead of putting energy into learning fertility awareness methods.

\section{Configuring the Not-Yet-Tracked Body}

Over the course of about ten years, I tried the contraceptive pill, had an IUD, so I had a copper coil, and I've had a hormonal Mirena coil. I've had the implant that goes in the arm. I tried a couple of different pills, so progesterone-only pill and a combined pill...Even I tried the diaphragm. I tried condoms. I tried pretty much everything...It either made me physically react badly...or made me emotionally feel like I was completely separate from myself. I felt very anxious and just unable to make decisions, and I felt like I wasn't myself at all. (Nicole, age 30, United Kingdom)

In recalling her contraceptive experiences before buying the tracker, Nicole's notyet-tracked body materializes as a painful entity. Equipped with different technological devices (pills, IUD, implant, diaphragm, condoms), she experienced either a disturbing body or a disappearing self. Like Nicole, other users describe a long and difficult history of contraception whereby technology would not allow them to align their body with their "embodied self" (Akrich and Pasveer 2016, 71). 
This experience of dissociation is complicated by social expectations about proper contraception. Users of fertility tracking often face disapprobation, especially from medical experts:

My doctor [in Canada at the time] said, "I hope you're using condoms as well." And I don't really want to argue with my doctor because I respect their opinion, but I also don't want to be on hormonal birth control and...he's never pressured me to be on it, but...that's the only real option that he's ever presented as something for me. Or use condoms. And I'm like, "I think there is another option for me [in fertility tracking] and I've done a lot of research that I think I'm informed enough to make the decision..." But it wasn't well-received from the doctor. (Chiara, age 30, the Cayman Islands)

The decision to use fertility tracking does not come lightly. Chiara spent five months gathering information before deciding to buy the tracker. She read articles online and the manual Taking Charge of Your Fertility. She joined a users' online forum and asked questions.

Stefanie (age 23) from Switzerland echoed that "the process of being convinced before buying [is] hard." She was inspired by a YouTuber narrating her experience with the tracker as a solution to get off of hormonal birth control. In Stefanie's, and many users' narratives, the tracker's appeal was in its promise of "no side effects." When acquiring the technology, Stefanie concurrently shifted her trust away from the pharmaceutical industry's discourses on hormonal birth control to the company's rhetoric on hormone-free tracking, through which the desirable fertile body is closer to nature, and free from unnecessary chemicals. This sentiment runs parallel to ecofeminist movements that seek to decolonize the body from capitalist appropriation; paradoxically, this particular "shift to nature" happens through the acquisition of an expensive technology.

The cost of the tracker (about US \$300) often delayed purchase by several months or years, most commonly because users cannot know beforehand if their body is a suitable candidate for the technology. Nevertheless, some used a cost-benefit approach to justify the expense. They explained that purchasing a tracker that could last a decade and then buying contraceptives only during red (fertile) or yellow (unknown) phases seemed more economical than buying contraceptives every day, month, or year. Whether acquiescing to a device or using it in service to their bodies, users perceived their bodies as "a site for an anticipatory, futureoriented calculation of value" (Murphy 2017, 115), a site for investment. 
The tracker constitutes self-fashioning users as responsible consumers and resourceful choice makers, a configuration paradigmatic of the "new moral economy of health care" that gave rise to multiple forms of biopolitics in the $1970 \mathrm{~s}$ (Murphy 2012, 101). The accounts discussed thus far present the tracker as a values-loaded object, with "built-in normativities" (Moser 2008). Yet Nicole, Chiara, and Stefanie should not be seen narrowly as either vulnerable victims of overarching forces or as rational fertility-optimizing consumers. Their entanglement in the fertility-tracking assemblage occurs in a gendered healthcare model of responsibility, where female subjects are expected to take reliable actions to manage their hormonal bodies, even if being denied real, practical choices (Roberts 2006).

\section{Menstrual Cycle Tracking and the Politics of Knowing}

Ovulation monitoring technologies regularly attract feminist criticism. Part of this critique challenges the predominant figure, in conventional Western epistemologies, of the ideal subject of knowledge as a neutral male observer who is separated from the object of study. Likewise, activists from the Fertility Consciousness Group in Cambridge, Massachusetts, argued that mechanical devices for cervical mucus tracking both keep women ignorant of their bodies and replace traditional indigenous forms of knowledge production (Bell et al. 1980, 32). Tia DeNora (1996) theorized that ovulation kits risk reinforcement of traditional gender binaries, as the kit delivers fertility status via "external and more authoritative confirmation to male observers" such as male partners or clinicians, whereas women are framed as passive, inexperienced objects upon which "modern Western" medicine is exerted (DeNora 1996, 375). More recently, Deborah Lupton (2015) warned that smartphone apps intensify self-surveillance regimes further within a digital knowledge economy and often without user's knowledge, particularly for women who want to take charge of their female reproductive bodies. However, feminist literature also suggests that the alienation-through-objectification critique is more complicated once we observe women's engagement with technologies in practice, as Charis Thompson (previously Cussins) (1996) demonstrated in her ethnographical fieldwork of infertility clinics in which women increased their agency through the objectification process, when desired.

Taking part in these debates from a feminist phenomenological perspective, this section asks, what does it take for a person and their body to become a willing and empowered subject for fertility-tracking technology? Fashioned by knowing of various sorts, different selves emerge in cyclic self-fashioning processes. 
By configuring the body as a site for interpretation, fertility-tracking subjects gain autonomy in specific situations, and challenge the presumed disciplinary power of technology. Izabella learned about digital fertility tracking from a colleague and, after some research, decided to buy a Daysy. Reflecting on her user history (more than two years and continuing), she described a shift in her willingness to rely on an external entity only to make sense of her fertility status:

At the beginning, I used it before reading anything about the method. I knew people were charting and taking their temperatures, but I didn't want to risk making the wrong assumptions. And I didn't want to manually enter numbers and make a decision. I wanted something easy that just tells me green, red, or yellow.

But then later, maybe one year after using it automatically, like a robot and reading and doing what it says, one friend recommended that book, Taking Charge of Your Fertility. I read it and then I started to go backward into my cycle and analyze the data. (Izabella, age 34, Switzerland)

While, like other users, Izabella had done some prior research on existing devices, she didn't deem it necessary to study the fertility-tracking method itself. Submitting her signaling-albeit-opaque body to the tracker was good enough, as Izabella expected to see a distinct color representing her fertility status. In those days, she described her body as a robot engaging in unprotected sex on green days, with reassurance of no side effects. But following the intervention of a friend and an authoritative fertility book, she transformed from willing object into an active interpreter of her cycle and fertility status. No longer afraid of making erroneous decisions related to her fertile body, she now "recodes" colors on occasion based on her body sensations, and on her readings. Like Izabella, other users shifted from automatically submitting their "bodies-to-be-known" to the tracker to becoming agents of interpretation. In such instances, the tracker loses its expert status as the user claims it for herself.

Some fertility-tracking users had the opposite transformation. It is beyond the scope of the current analysis to fully explain the conditions under which users will shift toward or away from agency through the tracker. However, several users became more trusting subjects of the technology after looking for information to make sense of their tracker, body, and/or data. When sources (such as books, friends, teachers, websites, customer services, and peers) gave confirmatory information, these users slowly adapted from a skeptical, interpretative position 
and trustingly delegated the interpretative work to the machine. For Jenny (age 28 , Finland), the shift occurred as she took an online class on fertility-tracking methods, after having used the tracker for a few months. Chiara spent considerable time asking questions and reading users' online discussion posts before buying the tracker, and later, trusting it. Cathy used an ovulation predictor kit to confirm the tracker's data: "I wanted to make sure the Daysy was actually accurate. I trusted that it was, I needed a controller, I needed another source to confirm it" (Cathy, age 33, US). The red light on the tracker matched the positive line from the ovulation kit, bolstering Cathy's trust in the tracker as she's engaging in sensory work to make sense of her body in a context of differently mediated data.

After being put to the test, the tracker sometimes becomes a kind of "digital companion species" (Lupton 2016), as the boundary between "device as tracker" and "subject as tracker" is blurred. Cathy describes her relation to the tracker's yellow light:

I think Daysy does a good job of using the yellow light. If there's anything that makes it doubt where my body might be going hormonally, it makes it a yellow day, which I find mostly frustrating [laughs]! But it's doing that to protect me.

Whereas a green or red light is perceived as useful information that buoys action, the bittersweet resignation Cathy describes when her protective tracker is uncertain about her status reveals a complex relationship. Regardless of fertility status, however, human and nonhuman entities combine through "data rituals" (Forlano 2017) to produce the fertile female body.

As the narratives show, the tracker rarely acquires a singular authoritative position. Its relative power to shape behavior is related to multiple elements, through which users themselves produce "serviceable truths" (Jasanoff 2015). The data operate as an active mediator between the body and the embodied self. The tracker, as "hybrid technology" (Mamo 2007), takes part in an intricate assemblage, which calls for the problematization of taken-for-granted considerations on the distribution of agency.

Rather than being merely empowered or alienated by technology, users subjectify themselves to a regime of attention I call "soft(a)wareness," which operates as a double imperative: users are prompted to know the body's internal logics (via objectifying software) while being prevented from access to the inner workings of 
the software itself (which is blackboxed). As a result, designers create a positive frame of "intentional non-knowing" (Owens 2017) that functions as a moral imperative for digitally mediated self-management. This cultural promotion of ignorance (Schiebinger 2005) works alongside the push for technologically mediated "self-knowledge." Users can rely on the tracker to know when to use contraception rather than their own embodied intuition, but they don't know the inner logics of the interpretative software, hidden from their realm of awareness.

Practically speaking, users enact varied versions of soft(a)wareness. These different versions occur within and between users. For example, early on in the cyclic self-tracking process, Izabella devoted minimal attention to her tracked body by submitting it like a robot to the tracker. Later on, she went beyond the tracker's scripted requirements to devote ample time and energy to understanding, observing, and analyzing her body and her embodied self. Some users kept tracking their cycle, but stopped using the tracker, once they become "confident enough" to do so. Nicole purchased a "smarter" tracker that allowed her to continuously track her temperature at night despite having to stand up regularly to feed her newborn. Margaret (age 26, US), on the contrary, turned to a basic thermometer to be less reliant on a costly technology.

When theorizing further the underlying conditions that shape users' reliance on external authority to make sense of their cycle, Emily Martin's (2001) classic work on women's experiences of menstruation is partially instructive. She found that class was a major factor in women's understandings. While middle-class women were more likely to give authority to scientific discourses-even if these conveyed negative stereotypes such as menstruation as failed pregnancy-working-class women were more able to resist these discourses and tended to account for the process in phenomenological terms. As the sample analyzed in this paper mostly includes highly educated subjects that would fall onto Martin's middle-class subjects categorization, such a factor doesn't help much to theorize about differences between women in this analysis. Certainly, differences in national contexts and access to particular types of healthcare systems will play a role. Other factors likely to impact such decisions would involve family and community contexts, risks associated with sex and fertility, marital or partnering status, and individual factors.

\section{Mediating Affects through Datafied Objectification}

Within the cyclic self-fashioning assemblage, the fertile body is inherently "multiple" (Mol 2002) and, though objectified, enacts specific "biopossibilities." 
Willey defines biopossibility as a "species- and context-specific capacity to embody socially meaningful traits or desires" (2016, 124). In cyclic self-tracking, the concept of biopossibilities is useful for critically engaging with natureculture entanglements in situations where the datafied body becomes a catalyst for understanding and intervening on the self. In these situations, users engage in the kind of "critical work" of "making [data] intelligible" that Willey recommends $(2016,139)$. They invest material aspects of the physical, biological, social, and digital body with potentiality and participate in particular regimes of truth (Willey 2016, 122).

Next, I investigate the critical work done by users in multiple configurations. In these configurations, users orientate themselves temporally to maintain or reach a certain level of comfort toward/with their body. They undertake orientations that align their "actual body" and their "potential body." Using Subramaniam and Willey's (2017) terminology, we can say that the potential body is characterized by users' understandings of "capital-B, Biology" (as the hegemonic field of Science), whereas their actual body refers to "lowercase-b, biology" (as the "stuff itself," enacted in bodies). Therefore, I define the actual body as the relation users enact with their present body, whereas the potential body is an imagined relation with their body that will, or could be, enacted in the future. The potential body is characterized by normative expectations of what the menstruating body should do. In the mediation of the relationship between their data and embodied self, users come to an understanding of their body, and the relations their body is in, in a way that allows them to moderate their affective relations with themselves and others.

The tracker is a key element (amongst others) in the project for harmonious attunement between the body and embodied self. For example, Lisbet describes synchronizing her life with her predicted menstrual status:

I am definitely less stressed out now because I take my time every month when I have my period. I actually plan on having down time... when my body is also having a down time...I understand why my body is doing this, and then it makes complete sense. And I can act like, what does my body need? It needs to relax now. And that's fine. And I actually plan for it, and that's perfect. (Lisbet, age 31, Denmark)

Lisbet's datafied cycle is a measure that goes beyond the binary code of fertility status. It is a measure of a future physical state ("down time") that it expected, anticipated, and, in her situation, accepted as positive. Her previous self, which 
was nondatafied, contributed to a lack of understanding about why her body behaved in a certain way. Robin uses her datafied cycle to make sense of her body and emotional states, when possible using the information to plan her day and her interactions. She said,

The very first thing you do in the morning sets a tone for the day...[The measure] helped me to get to a better question faster. So, if I feel irritated...it helped me to get to "OK, why am I feeling this?" faster, so I can avoid being a big jerk. And accusing others of being a big jerk...I'm going to adjust the day today. Or I'm just not going to talk to these people today because I'm not going to be nice [laughs]. (Robin, age 42, US)

In situating her body on the fertility chart and using that data to understand her emotions, Robin's account demonstrates how the datafied body can become a mediator of relations to others which, in this case, are enacted through avoidance.

Overall, fertility-tracking users viewed the prospective aspects of the technology as highly practical, especially for aiding their mental and physical preparedness to manage reproductive realities at different points in the life course. The diversity of age in this sample illuminates various ways users in different phases wished to be prepared. For example, unlike most users, Robin's motivation to use the device was never for "contraceptive use" but to monitor menopause. She was expecting her body to start changing and was willing to "do that [menopause] well." For Robin, "doing menopause well" meant "enjoying [her] menopausal problems" by understanding what her body will be doing; her data-driven approach takes part in "local biologies" that challenge negative views of the aging body perpetuated by disease-oriented approaches to menopause (Lock 1993).

With a focus on the potential body, users like Robin engaged in varied anticipatory practices (Adams, Murphy, and Clarke 2009) in response to cyclic data (such as taking medications, eating hormone-modifying plants or seeds, and using essential oils, to name a few). In some narratives, the datafied cycle was retrospectively viewed as a gauge of well-being. In these situations, users related how living in harmful social environments was reflected in their cycle chart. To "redress" the aberrant data, these users tried to modify their entanglements with these environments whenever possible. This was the case for Margaret (age 26, US) who got an impulse to move out of an unstable living situation and relationship based on her data (recurrent anovulatory cycles). When she observed 
that her chart switched back to seemingly ovulatory following the spatial and relational change, the data confirmed to her that she had made the right choice.

Cyclic self-fashioning is a process that involves not only what users feel but also who they are, as biosociotemporal entities. In this process, users and data are coshaped in a "looping effect" (Hacking 2002) in which individuals, when classified, tend to spontaneously align with the prescriptive characteristics of the classifications; once in the loop, classifications get modified in return. For fertilitytracking users, the charts (or dots, or lights) become "agents" that constitute bodies and selves (Dumit and de Laet 2014). These outputs not only characterize bodies as temporary cyclical entities; they produce an ontological reality, the cyclic self.

\section{The Cyclic Self as Body Politics}

Through processes of cyclic self-fashioning, multiple selves emerge, such as the "active knowledge-seeker" or the "affects mediator" described previously. In this section, I analyze three other emerging configurations that challenge or reproduce gendered expectations for the female body: the "maximizing self," "the erotic self," and the "invalidated self."

One configuration is the maximizing self. If we return to Izabella-who uses her embodied intuition along with the tracker outputs to produce her fertility statusone motivation was to increase the number of green days: "I am trying to maximize the number of green days which I know exist. And I know that Daysy is being more conservative than it should be." As she explains, Daysy gives her "a little bit of buffer in order to make it safer for everybody." This standardization is deemed "too conservative"; therefore, she interprets some yellow and red dots as green. The maximizing self can also be enacted through behavioral actions. For example, Linda takes medicinal plants to increase the length of her cycle and get more green days (age 26, US). Contrary to Izabella, Linda doesn't recast the tracker's outputs, but tries to act earlier in the process by altering her body's hormone balance. Yet in the narratives, maximizing the number of green days is not a goal in itself. It is a way to be reassured that one's body is working "as it should." Green days can be associated with the "conceptive imperative" (Wilkinson, Roberts, and Mort 2015) in which menstruating subjects understand themselves as primarily fecund entities. But the notion of cyclic self also challenges the reduction of the female body to procreative capacities, as seen with Robin's menopause tracking. 
The exploration of another configuration, the erotic self, leads beyond widely discussed themes in the datafication of health (Ruckenstein and Schüll 2017). For example, Jane (age 21, US) associates green days with the bliss of "deequipment." In her description, green light signifies "fun" defined as sexual intercourse without contraception. When communicating her colored data to her partner, she imbues the data point with a coupled identity, toggling between "I'm green" and "We're green" in her reporting. As when couples share news that "We're pregnant," Jane implies that her partner is fully invested in the outcome. Similarly, Christine (age 24, US) was sending screenshots of her colored prognostic to her closer partner in order to plan safe dates for unprotected sex. The mobilization of data in service of anticipated, pleasurable sexual activities serves as a means to eroticize users' embodied self. The erotic self is, in that sense, powerful and relational (Willey 2016).

Cyclic self-fashioning also creates "embodied differences" (M'charek 2010) that materialize in a failed relationship with the "digital companion species" when the user's body does not meet technological specifications. In such cases, users become invalidated. This was the case for Adeline (age 34, US). She had been using the tracker to avoid pregnancy for several years. When she and her husband decided to conceive a child, they used the tracker to help pinpoint optimal cyclic timing. After several months, she was still not pregnant. Despite assessments at infertility clinics, there was no clear reason why. The tracker had made Adeline fertile, but never pregnant. The disconnect resulted in pain and frustration toward the tracker. She explained, "It gave me a false sense of control or knowledge about what was happening with my body"; her potential body never materialized. Tess's (age 31, US) invalidation resulted from being unable to use the tracker properly, as she almost always received that inconclusive yellow light. Instead of agency, she received daily confirmation of an "uncertain" rather than "cyclic" body that was stressful enough for her to want to stop using the device.

Cyclic self-fashioning processes shape multiple distributions of the self, through which users align multiple elements, including their embodied self, datafied cycle, relations with others, biomedical knowledge, experiential knowledge, bodily sensations, and others. In these distributions, the role of Biology (as the biomedical system of reference) and biologies (as experienced bodies) is ambivalent, potentially acting as both validating as well as invalidating entities (Subramaniam and Willey 2017). If we are to problematize the role of B/biology in users' lives, it is important to acknowledge the dual tension in which they are intricated. 
On the one hand, users' anticipatory practices seem to fit well in a gendered model of healthcare characterized by moral imperatives, where female subjects are prompted to act towards the preservation and optimization of "their best possible futures" (Adams, Murphy, and Clarke 2009); an imperative of the "idealized reproductive citizen" strengthened by digital technologies (Lupton 2015). On the other hand, by engaging in data rituals, they enact a particular form of care (Forlano 2017). Acting with, rather than against their body, users challenge negative representations of the female body as chaotic, and menstruation as a failure (Martin 2001).

Users who find, in data, socially acceptable reasons for their emotions and behaviors represent a form of embodiment of the self, in which lowercase-b biology is used as a validating entity, even while edging towards what could be seen as biologism. Yet while certain biologies are normalized and therefore validated in cyclic self-fashioning, others are not. In this sense, processes of cyclic self-fashioning also (re)produce embodied differences that result in the labeling of "non-conforming" bodies-a process of technologically based scrutiny that can be a source of pain and anxiety rather than empowerment.

\section{Discussion}

This paper has two aims: (1) to provide empirical insights on self-tracking practices heretofore neglected in self-tracking scholarship, and (2) to provide a conceptual framework for the analysis of self-tracking practices based on feminist theories of the body and technology. Investigating "cyclic-selves fashioning" as resultant of the sociohistorically situated alignment among digital data, technology, and the female body provides insight into new understandings of the conditions under which self-tracking technologies of the menstrual cycle reproduce and challenge power relations, as well as (re)configure women's experiences of health, fertility, and sexuality. By situating the multiple and complex negotiations that necessarily occur between users, technology, and the body as a particular site of power, the presentation herein offers an analytical toolkit that allows for the description of self-tracking practices, without ultimately portraying users as victims of technology or technology as deterministic.

By emphasizing varied enactments of menstrual cycle tracking, it shows how tracking practices shape physiological "facts" about the fertile female body while also promoting a particular relation to the body and self. Throughout the twentieth century, different proxies have been used to construct the technoscientific figure of the female body as a predominantly cyclical entity. I use 
the concept of cyclic self-fashioning to explore how the premise of cyclicity embedded in the technology works to reduce the complexity of bodies to a simple set of color-coded indicators whilst opening them up to question, discussion, and intervention. Building on feminist studies of objectification (Cussins 1996), anticipation (Adams, Murphy, and Clarke 2009), and materialization (Willey 2016), I describe how users mobilize varied sources of authority when confronted with the material agency of objectifying technologies.

This paper opens a dialogue with feminist inquiries to illustrate that self-tracking subjects are multiple rather than singular. Fertility-tracking can be seen both as a way to resist the increasing biomedicalization of women's bodies as well as a means to perpetuate neoliberal imperatives such as the responsible, reproductive citizen in charge of her health. Feminist scholars have similarly argued that processes of "self-care" are conflicting: self-care as privilege bears potential for reproducing neoliberal imperatives that lead to self-empowerment rather than social change (Bobel 2010, 84); yet, self-care enacted as political action (as seen in the context of political struggle against anti-Black racism [Ahmed 2014]) may also bring about change.

This study falls in between, and may be more aptly framed in terms of "selfdetermined care"-a reframing of self-care that builds social justice through love, and against the devaluation of certain lives (Brown 2012). By aligning individual and collective practices in pursuit of social justice, self-determined care may be a means to address the exclusionary effects of self-tracking practices. In turn, we might find a way out of the alienation/liberation narrative in which women's uses of technologies so easily get classified.

As a feminist technoscience researcher, my aims and hopes are that academic knowledge production can be used for feminist intervention (and not just theory per se). A cadre of radical, self-determined menstrual activists have already started to build collective projects for the design of feminist menstrual cycle tracking technologies. For example, mobile apps such as drip or POW! are being developed in an attempt to give more agency to users when it comes to privacy, transparency, or data ownership. ${ }^{2}$ Another project to be mentioned is Hamdamapp, ${ }^{3}$ an app that allows users in Iran and Afghanistan to track their cycle on the Djalali calendar and provides non-heteronormative information about sex and health. As designers are beginning to develop queer technology that helps individuals to imagine constructive and positive ways to live with our bodies, we need feminist studies to engage with emerging technologies if we want our 
research to go beyond theoretical abstraction and offer benefit to our subjects and broader communities.

This paper offers a reflection on the ways a specific fertility-tracking assemblage shapes and is shaped by different entities, temporalities, and affects. Future research could investigate the conditions under which some users in specific assemblages shift toward and away from agency, and in whose interests. In addition to the investigation of such dynamics, I hope that this paper could encourage future research on the differences and power hierachies pertaining to race, (dis)ability, (non-normative) sexuality and gender spectrum that are enacted through these technologies. That way we can not only deepen our understanding of human entanglements with data, but also make critical and intersectional interventions.

\section{Acknowledgements}

I am grateful to my interviewees for generously sharing their experiences with me, and to Valley Electronics for kindly granting me access to their survey. I thank Luna Dolezal, Venla Oikkonen, and the Catalyst editorial team for their insightful comments. Many thanks to Amy Agigian, Chris Bobel, Denia Djokić, and Francesco Panese for helping me shape my earlier thoughts through lively and inspiring discussions. I am grateful to Mélody Pralong, and Kathrin Zippel for their comments on a previous version of the introduction. Many thanks to the two anonymous reviewers for their invaluable suggestions, and to Gayle Sulik for her thoughtful editing of this paper. Finally, I am deeply grateful to my writing friends from the Boston Consortium for Graduate Studies in Gender, Culture, Women, and Sexuality, Christine Bachman-Sanders, Deborah Feingold, Heatherjean MacNeil, Katharina Neissl, Lauren Rizzuto, and Asha Tall, for their extremely helpful feedback and fantastic support.

\section{Notes}

${ }^{1}$ I use the terms woman, she, her to refer to the way specific narrators (for example, designers, users, or authors) frame the subject. Otherwise, the genderneutral terms user, they, them are preferred.

${ }^{2}$ See https://bloodyhealth.gitlab.io/ for the drip app, and https://www.usepow.app/ for POW!

3 See https://hamdamapp.com/ for Hamdamapp. 


\section{References}

Adams, Vincanne, Michelle Murphy, and Adele E. Clarke. 2009. "Anticipation: Technoscience, Life, Affect, Temporality." Subjectivity 28 (1): 246-65.

Ahmed, Sara. 2014. "Selfcare as Warfare." Feministkilljoys (blog). August 25, 2014. https://feministkilljoys.com/2014/08/25/selfcare-as-warfare/.

Akrich, Madeleine, and Bernike Pasveer. 2004. "Embodiment and Disembodiment in Childbirth Narratives." Body \& Society 10, no. 2-3 (June): 63-84. https://doi.org/10.1177/1357034X04042935.

Bell, Susan, Paula Garbarino, Jeanne Hubbuch, Adrienne Ingrum, Lyn Koehnline, and Jill Wolhandler. 1980. "Reclaiming Reproductive Control: A Feminist Approach to Fertility Consciousness." Science for the People 12 (1): 6-9, 30-35.

Bobel, Chris. 2010. New Blood: Third-Wave Feminism and the Politics of Menstruation. New Brunswick, NJ: Rutgers University Press.

Brown, Adrienne Maree. 2012. "How about a Beginning of Self-Determined Care?" October 15, 2012. http://adriennemareebrown.net/2012/10/15/how-about-abeginning-of-self-determined-care/.

Clarke, Adele E. 2000. "Maverick Reproductive Scientists and the Production of Contraceptives, 1915-2000+." In Bodies of Technology: Women's Involvement with Reproductive Medicine, edited by Ann Rudinow Saetnan, Nelly Oudshoorn, and Marta Kirejczyk, 37-89. Columbus: Ohio State University Press.

Cussins, Charis. 1996. "Ontological Choreography: Agency through Objectification in Infertility Clinics:" Social Studies of Science, no. 26, 575-610.

Danesi, Giada, Mélody Pralong, Francesco Panese, Bernard Burnand, and Michèle Grossen. 2020. "Techno-Social Reconfigurations in Diabetes (Self-) Care." Social Studies of Science 50 (2): 198-220.

Davis, Mark. 2015. "After the Clinic? Researching Sexual Health Technology in Context." Culture, Health \& Sexuality 17 (4): 398-411.

DeNora, Tia. 1996. "From Physiology to Feminism: Reconfiguring Body, Gender and Expertise in Natural Fertility Control." International Sociology: Journal of the International Sociological Association 11 (3): 359-83.

Dumit, Joseph. 1998. "A Digital Image of the Category of the Person: PET Scanning and Objective Self-Fashioning." In Cyborgs and Citadels: Anthropological Interventions in Emerging Sciences and Technologies, edited by Gary Lee Downey and Joseph Dumit, 83-102. Santa Fe, NM: School of American Research Press. 
Dumit, Joseph, and Marianne de Laet. 2014. "Curves to Bodies: The Material Life of Graphs." In Routledge Handbook of Science, Technology, and Society, edited by Daniel Lee Kleinman and Kelly Moore, 71-89. Hoboken, NJ: Taylor and Francis.

Forlano, Laura. 2017. "Data Rituals in Intimate Infrastructures: Crip Time and the Disabled Cyborg Body as an Epistemic Site of Feminist Science." Catalyst: Feminism, Theory, Technoscience 3 (2): 1-28.

Hacking, Ian. 2002. "Inaugural Lecture: Chair of Philosophy and History of Scientific Concepts at the Collège de France, 16 January 2001." Economy and Society 31 (1): 114 .

Henwood, Flis, and Benjamin Marent. 2019. "Understanding Digital Health:

Productive Tensions at the Intersection of Sociology of Health and Science and Technology Studies." Sociology of Health \& Illness 41 (S1): 1-15.

Horrocks, Stephen. 2019. "Materializing Datafied Body Doubles: Insulin Pumps, Blood Glucose Testing, and the Production of Usable Bodies." Catalyst: Feminism, Theory, Technoscience 5 (1): 1-26.

Jasanoff, Sheila. 2015. "Serviceable Truths: Science for Action in Law and Policy." Texas Law Review 93 (7): 1723-50.

Lock, Margaret. 1993. Encounters with Aging: Mythologies of Menopause in Japan and North America. Berkeley: University of California Press.

Lupton, Deborah. 2015. "'Mastering Your Fertility': The Digitised Reproductive Citizen [Preprint]." In Negotiating Digital Citizenship: Control, Contest and Culture, edited by Anthony Mccosker, Sonja Vivienne, and Amelia Johns, 81-92. London: Rowman and Littlefield.

_. 2016. "Digital Companion Species and Eating Data: Implications for Theorising Digital Data-Human Assemblages." Big Data \& Society 3 (1): 1-5.

Mamo, Laura. 2007. "Negotiating Conception: Lesbians' Hybrid-Technological Practices." Science, Technology, \& Human Values 32 (3): 369-93.

Martin, Emily. 2001. The Woman in the Body: A Cultural Analysis of Reproduction. Boston: Beacon Press.

M'charek, Amade. 2010. "Fragile Differences, Relational Effects: Stories about the Materiality of Race and Sex." European Journal of Women's Studies 17, no. 4 (November): 307-22. https://doi.org/10.1177/1350506810377698.

Mol, Annemarie. 2002. The Body Multiple: Ontology in Medical Practice. Durham, NC: Duke University Press. 
- 2015. "Who Knows What a Woman Is...: On the Differences and the Relations between the Sciences." Medicine Anthropology Theory 2 (1).

https://doi.org/10.17157/mat.2.1.215.

Moser, Ingunn. 2008. "Making Alzheimer's Disease Matter: Enacting, Interfering and Doing Politics of Nature." Geoforum, Environmental Economic Geography 39 (1): 98110.

Murphy, Michelle. 2012. Seizing the Means of Reproduction: Entanglements of Feminism, Health, and Technoscience. Durham, NC: Duke University Press.

—. 2017. The Economization of Life. Durham, NC: Duke University Press.

Owens, Kellie. 2017. "Too Much of a Good Thing? American Childbirth, Intentional Ignorance, and the Boundaries of Responsible Knowledge." Science, Technology, \& Human Values 42 (5): 848-71.

Roberts, Celia. 2006. "'What Can I Do to Help Myself?' Somatic Individuality and Contemporary Hormonal Bodies." Science \& Technology Studies 19 (2): 54-76.

Roy, Deboleena, and Banu Subramaniam. 2016. "Matter in the Shadows: Feminist New Materialism and the Practices of Colonialism." In Mattering: Feminism, Science, and Materialism, edited by Victoria Pitts-Taylor, 23-42. New York: NYU Press.

Ruckenstein, Minna, and Natasha Dow Schüll. 2017. "The Datafication of Health." Annual Review of Anthropology 46 (1): 261-78. https://doi.org/10.1146/annurevanthro-102116-041244.

Schiebinger, Londa. 2005. "Agnotology and Exotic Abortifacients: The Cultural Production of Ignorance in the Eighteenth-Century Atlantic World." Proceedings of the American Philosophical Society 149 (3): 316-43.

Sharon, Tamar. 2015. "Healthy Citizenship beyond Autonomy and Discipline: Tactical Engagements with Genetic Testing." BioSocieties 10 (3): 295-316.

_. 2016. "Self-Tracking for Health and the Quantified Self: Re-Articulating Autonomy, Solidarity, and Authenticity in an Age of Personalized Healthcare." Philosophy \& Technology 30 (April): 1-29.

Shaw, Carolyn Martin. "Body Politics." In Encyclopedia of Race and Racism, edited by John Hartwell Moore. Detroit: Thomson Gale, 2008.

Subramaniam, Banu, and Angela Willey. 2017. "Introduction: Feminism's Sciences." Catalyst: Feminism, Theory, Technoscience 3 (1): 1-23.

Timmermans, Stefan, and Iddo Tavory. 2012. "Theory Construction in Qualitative Research: From Grounded Theory to Abductive Analysis." Sociological Theory 30 (3): 167-86. https://doi.org/10.1177/0735275112457914. 
Viseu, Ana, and Lucy Suchman. 2010. "Wearable Augmentations: Imaginaries of the Informed Body." In Technologized Images, Technologized Bodies, edited by Jeanette Edwards, Penelope Harvey, and Peter Wade, 161-84. New York: Berghahn Books.

Waidzunas, Tom, and Steven Epstein. 2015. "'For Men Arousal Is Orientation': Bodily Truthing, Technosexual Scripts, and the Materialization of Sexualities through the Phallometric Test." Social Studies of Science 45 (2): 187-213.

Weiner, Kate, Catherine Will, Flis Henwood, and Rosalind Williams. 2020. "Everyday Curation? Attending to Data, Records and Record Keeping in the Practices of SelfMonitoring." Big Data \& Society 7 (1): 1-15.

Wilkinson, Joann, Celia Roberts, and Maggie Mort. 2015. "Ovulation Monitoring and Reproductive Heterosex: Living the Conceptive Imperative?" Culture, Health \& Sexuality 17 (4): 454-69. https://doi.org/10.1080/13691058.2015.1005671.

Willey, Angela. 2016. Undoing Monogamy: The Politics of Science and the Possibilities of Biology. Durham, NC: Duke University Press.

\section{Author Bio}

Laetitia Della Bianca is a PhD candidate in the Faculty of Social and Political Sciences at the University of Lausanne. Her current research explores the role of scientific authority in the shaping of biosensors, knowledges, and bodies. 